\title{
Maximizing Millennial Students Role in Combating COVID-19 Hoaxes and Myths
}

\author{
Astri Dewayani ${ }^{1,2^{*}(\mathbb{D})}$, Euvanggelia Dwilda ${ }^{3^{(i)}}$, Rizki Putra Prastio $^{4^{(i)}}$, Indah Fahmiyah $^{4^{(i)}}$,

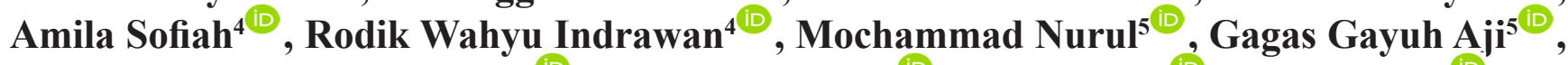 \\ Nanda Rachmad Putra Gofur ${ }^{(\mathbb{D})}$, Siti Khaerunnisa ${ }^{\left.7^{(\mathbb{D}}\right)}$, Dewi Sriani ${ }^{(\mathbb{D}}$, Yankel Sena ${ }^{(\mathbb{D})}$ \\ ${ }^{1}$ Department of Anatomy, Histology and Pharmacology, Faculty of Medicine, Universitas Airlangga, Surabaya, Indonesia \\ ${ }^{2}$ Department of Infectious Disease Control, Faculty of Medicine, Oita University, Yufu, Japan \\ ${ }^{3}$ Midwifery Study Program, Faculty of Medicine, Universitas Airlangga, Surabaya, Indonesia \\ ${ }^{4}$ Department of Engineering, Faculty of Advanced Technology and Multidisipline, Universitas Airlangga, Surabaya, \\ Indonesia \\ ${ }^{5}$ Department of Business, Faculty of Vocational Studies, Universitas Airlangga, Surabaya, Indonesia \\ ${ }^{6}$ Department of Health, Faculty of Vocational Studies, Universitas Airlangga, Surabaya, Indonesia \\ ${ }^{7}$ Department of Physiology and Medical Biochemistry, Faculty of Medicine, Universitas Airlangga, Surabaya, Indonesia \\ ${ }^{8}$ Department of Accounting, Faculty of Economic and Business, Universitas Airlangga, Surabaya, Indonesia \\ ${ }^{9}$ Department of Radiology, Oita University, Yufu, Japan
}

\section{A R T I C L E I N F O}

\section{Article history:}

Received 19 May 2021

Received in revised form 24 June 2021

Accepted 28 June 2021

Available online 30 June 2021

Keywords:

COVID-19,

Health education,

Misinformation,

Millennials,

Perception

*) Corresponding author:

astri.dewayani@fk.unair.ac.id

\begin{abstract}
A B S T R A C T
Introduction: Since the outbreak of Corona Disease-19 (COVID-19) spreads all over the world, various ways of health attempts have been conducted. However, overflowed information intertwines with mis/disinformation could raise public anxiety and stigma-related diseases. We aimed to assess the help of the young generation of millennials and Gen-Z whom are active college students in debunking hoaxes and myths of COVID-19 into their community.

Methods: The selected students were given a short course on COVID-19 basic information, prevention, and circulated myths. Later, they become ambassadors and actively educated via offline and online platforms. The impact of outspread information on audiences was investigated through a qualitative survey.

Results: The knowledge of students were measured by pre- and post-test within the short course. Prior knowledge showed the least understanding part was prevention and the myth of COVID-19 related treatments and severities of disease. There was a significant improvement of knowledge in post-test after receiving seminar $(\mathrm{p}=0.0002)$. There were 97 respondents who filled the online survey that predominantly in young adulthood age. Respondent's insight was enhanced and they likely intend to spread the actual information to their surroundings.

Conclusion: Appointing student as the spokesperson for health education can raise their social responsibility. Clarifying misinformation and health behaviour could be more influential within the same sharing community. In addition, the use of various online platforms could efficiently reach massive target, especially young ages.
\end{abstract}

\section{Introduction}

Since the emerge of unusual pneumonia-like disease in December 2019 in Wuhan, China, followed by the outbreak of Corona Disease-19 (COVID-19) declaration by the World Health Organization (WHO) in March $2020,{ }^{1}$ the world has faced tremendous pandemic states. Various way of public health efforts has been attempted, including physical distancing, health hygiene protocols, and travel restrictions to slow the transmission rate. On top of these managements, with the vast use of internet websites, instant messaging services, and social media, public has overflowed by immense information relating to COVID-19 that became "infodemic" 2 throughout numerous platforms such as Twitter3 or Facebook. ${ }^{4}$ This possesses an equal threat towards COVID-19 public health responses, as people find difficulties in finding credible sources as well as increase public anxiety and stigmarelated disease. The perceived informations could shaped 
public perception in major domains - beliefs (severity and impact of the pandemic), knowledges (source and health literacy), behaviours (hygiene and social distancing).

Skepticism in science undermines progress in medicine, echoing from mouth-to-mouth, social media, even some influential figures. These conditions have made society disbelief to aware and affected the behavior. According to Chou et al., health misinformation is a health-related claim of fact that is currently false due to a lack of scientific evidence. $^{5}$ In an extensive way, the phrase might adopt 'fake news' or hoax term, which conflates misinformation and disinformation. Misinformation is a false information, but the person who is disseminating it believes that it is true. Meanwhile, disinformation is a knowingly false information by the person and intentionally spreading it. ${ }^{6}$ As the fourth most populous country in the world and encompasses thousands of islands, Indonesia has suffered greater losses in pandemic battle. While many countries in Europe and Asians had reported enormous cases, yet Indonesia did not prepare well enough. By mid-year 2020, total cases had reached 31.000 cases across the nation with no sign of flattened out. ${ }^{7}$ This widespread might result of government policy with lack of coordination among bureaucrats had raised misleading to controversial within community responses,${ }^{8}$ continue by the annual religion homecoming 'mudik' without a proper understanding of health protocol could violate the prevention mandate. ${ }^{7}$ In addition, general misinformation to conspiracy belief hoaxes keeps circulating as people like to gather around and tell a story. ${ }^{9}$

The millennials evolve alongside technology throughout adulthood, making them adapted to changes in social media platforms. Simultaneously, as young adolescents, Gen-Z also has a strong presence in online media though newer than millennials. ${ }^{10}$ Both generations are active as student or academic fellow in college in this decade. Empowering students to spread health education wisely and globally in social media could help fight 'fake news' in order to boost the community's major perceptions and prevent social stigma. ${ }^{11}$ Therefore, health education becomes essential to prevent a new catastrophe when fighting this pandemic.

In this study, we raised the voice of students by forming an anti-hoax of COVID-19 ambassador of Universitas Airlangga. Majority of participants were non-medical students to equalize with the general public's perception. Their presence hoped could help in educating prevention, debunking the myths and emphasizing the importance of community attachment to their neighborhood also social media globally.

\section{Methods}

This was a part of community service activities of Universitas Airlangga program 'Barisan Melawan Hoax COVID-19 (BRONVID)' conducted in December 2020. This study applied a qualitative method, an appropriate approach to display the social response and interaction. The impact on student knowledge and information later investigated through a qualitative survey.

\section{Establishing Anti-Hoax Ambassador}

We built an interconnection team across faculties to browse the current community dilemma and create the base of ambassador qualification. The criteria are a student of Universitas Airlangga, has a general knowledge of COVID-19, and willing to participate.

All the participants attended an online short course seminar for one day, comprised of general knowledge of SARS-CoV-2 virulence and transmission, individual and community prevention step also facts and myths that vastly circulated, given by the experts. Participants' knowledge was evaluated through multiple choice questions pre-and post-test related to the material. Following that, participants received materials on creating wise and exciting social media content to compose COVID-19 information.

The ambassadors had to educate the environment around them, including the nuclear family, neighbors, and friends both offline (face-to-face) and online (social media and instant messaging services). They were allowed to create any graphics or use content from the seminar. All materials were made available online through social media thus the public can have access to them.

\section{Data Collection}

The audiences were given an online qualitative survey after receiving information from the ambassador. General information related to age, education, and occupation were collected. The question consists of the quality of information, how their thought after got the information, how their awareness raised using 4-point bipolar agreement scales (strongly disagree, disagree, agree, and strongly agree). The survey was made in Google form. All data were obtained from December 6 to 8, 2020.

\section{Data Analysis}

Data regarding the ambassador knowledge were expressed as mean (standard deviation) and carried out by Student t-test (two-tail). The respondents from the audience consisted of 97 persons. The collected data were analyzed in tabulation (frequencies (percent) or mean) and displayed descriptively. Statistical analysis was carried in GraphPad ver. 8 software program with $\mathrm{p}<0.05$ considered as statistically significant.

\section{Results}

Improvement of COVID-19 Ambassador's Knowledge There were 21 university students willing to participate as the ambassador across 1st year to 3rd year from several faculties. They were given a pre-test to measure their prior knowledge before starting the seminar. Besides major points in the questions, all ambassadors got details information of the widespread myths 12 (temperature vs. virus, virus in the air, virus transmitted from package, racist and virus origin, and treatment for COVID-19).

It was shown that all ambassadors understood the etiology and transmission of COVID-19. On the other hand, the ambassador found less understanding in the myths and prevention section, which had improvement though not all ambassadors got the correct answer (Table $1)$. The statistics also show that the ambassadors had less comprehension in what places to avoid, for instance, 3C places (Closed space, Crowded condition, Conversation in closed range) as part of social distancing. It was also observed that the ambassadors believe the death from COVID-19 only happened in aged people or with comorbid.

Overall, there was a notable improvement of comprehension after education, where more than half of 
the ambassadors gained 80 score above (Table 2). The average score significantly increased, as seen in the posttest score $(\mathrm{p}=0.0002)$ (Figure 1a).

Table 1. COVID-19 Ambassador's Knowledge Responses

\begin{tabular}{ccc}
\hline Question Number & \multicolumn{2}{c}{ Correct responses (n) } \\
\hline & Pre-test & Post-test \\
\hline Q1 & 21 & 21 \\
\hline Q2 & 21 & 21 \\
\hline Q3 & 19 & 21 \\
\hline Q4 & 13 & 19 \\
\hline Q5 & 4 & 10 \\
\hline Q6 & 20 & 20 \\
\hline Q7 & 21 & 21 \\
\hline Q8 & 18 & 21 \\
\hline Q9 & 5 & 10 \\
\hline Q10 & 15 & 17
\end{tabular}

Q1. The cause of COVID-19; Q2. Which system is affecting by COVID-19 affecting; Q3. COVID-19 spreading through; Q4. One of COVID-19 symptom, except; Q5. One of 3C in prevention; Q6. One of mask type for prevention, except; Q7. One of fact regarding COVID-19; Q8. Is someone recovered from COVID-19 could re-infect again?; Q9. Is death case from COVID-19 only patient with comorbid?; Q10. What is the gold standard in diagnosing COVID-19.

Table 2. Ambassador test score

\begin{tabular}{cccc}
\hline Test score & \multicolumn{2}{c}{ Total responses $(\mathrm{n}=21)$} & p value \\
\cline { 2 - 3 } & Pre-test & Post-test & \\
\hline$<60$ & 1 & 0 & $0.0002^{*}$ \\
\hline $60-80$ & 19 & 10 & \\
\hline$>80$ & 1 & 11 & \\
\hline Total & 21 & 21 & \\
\hline Mean & 74.76 & 86.19 & \\
*paired t-test & &
\end{tabular}

After improving knowledge, the ambassadors were given materials to create interesting content and increase social media engagement. We demonstrated a poster containing health information then followed by the ambassadors (Figure 2). The educational contents was unrestrained on how ambassador wants to convey the messages, however it should contain each point of transmission, prevention, and myth. All ambassadors gave education offline and online. For online, all of them used Instagram, while few added other platforms such as YouTube and TikTok (Figure 1b).

\section{Analysis of Respondents Insight After Education}

\section{Respondent Characteristic}

Of total 97 respondents that filled the questionnaire, $(65$, $67.01 \%$ ) were female, mostly in adulthood age 15-25 years old $(77,19.38 \%)$ and were friend of the ambassador $(50,51.55 \%)$. Since the majority were friends, the occupation covers students $(54,55.67 \%)$ and college students $(15,15.46 \%)$. There were minority jobs such as housewife, job seeker, taxi bike that combine into others $(12,12.37 \%)$. Respondent predominantly had not received any COVID-19 education before (79, 81.44\%) (Table 3).

Table 3. Respondent characteristic

\begin{tabular}{|c|c|c|}
\hline Characteristics & $\mathrm{n}=97$ & $\%$ \\
\hline \multicolumn{3}{|l|}{ Sex } \\
\hline Male & 32 & $32.99 \%$ \\
\hline Female & 65 & $67.01 \%$ \\
\hline \multicolumn{3}{|l|}{ Age } \\
\hline $15-25$ years & 77 & $79.38 \%$ \\
\hline 26-39 years & 4 & $4.12 \%$ \\
\hline $40-49$ years & 8 & $8.25 \%$ \\
\hline 50 years and over & 8 & $8.25 \%$ \\
\hline \multicolumn{3}{|l|}{ Education } \\
\hline Bachelor/Posgraduate & 29 & $29.90 \%$ \\
\hline Elementary School & 1 & $1.03 \%$ \\
\hline Senior High School & 62 & $63.92 \%$ \\
\hline Junior High School & 5 & $5.15 \%$ \\
\hline \multicolumn{3}{|l|}{ Occupation } \\
\hline Student & 54 & $55.67 \%$ \\
\hline College Student & 15 & $15.46 \%$ \\
\hline Public Officer & 5 & $5.15 \%$ \\
\hline Private Worker & 6 & $6.18 \%$ \\
\hline Entrepreneur & 5 & $5.15 \%$ \\
\hline Other & 12 & $12.37 \%$ \\
\hline \multicolumn{3}{|l|}{ Ambassador's Relation } \\
\hline Family & 29 & $29.90 \%$ \\
\hline Friend & 50 & $51.55 \%$ \\
\hline Neighbor & 18 & $18.56 \%$ \\
\hline \multicolumn{3}{|l|}{$\begin{array}{l}\text { Had COVID-19 educa- } \\
\text { tion before? }\end{array}$} \\
\hline No & 79 & $81.44 \%$ \\
\hline Yes & 18 & $18.56 \%$ \\
\hline
\end{tabular}

\section{Respondent's insight}

The online survey answer indicated that the ambassador was capable enough to give much information that was quickly understood and actively providing accurate answers to the question that the audience did not comprehend. More than $90 \%$ of respondents agreed that the explanation could increase their insight (Figure 3a). However, all ambassadors acquitted themselves in the contents thus we cannot measure respondents comprehension in a specific point.

As seen in Figure $3 b$, respondents were asked about their recognition and belief toward hoax after ambassador explanation. Their response was strongly disagreed and disagreed to believe hoaxes, 40 person (41\%) and 35 persons (37\%), respectively. However, a small number of respondents still confusedly believe (22 people, $23 \%$ ). Despite that, respondents have more awareness of COVID-19 and want to spread the correct information to their surroundings. 
(a)

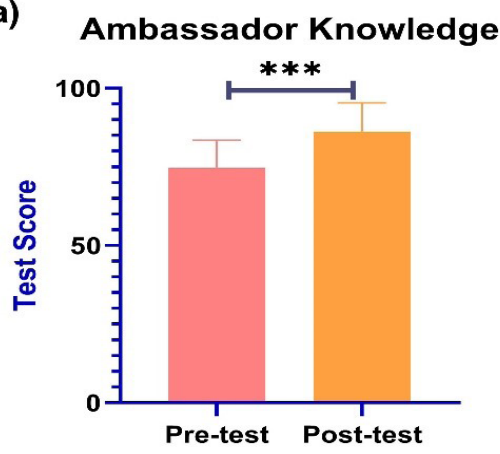

(b)

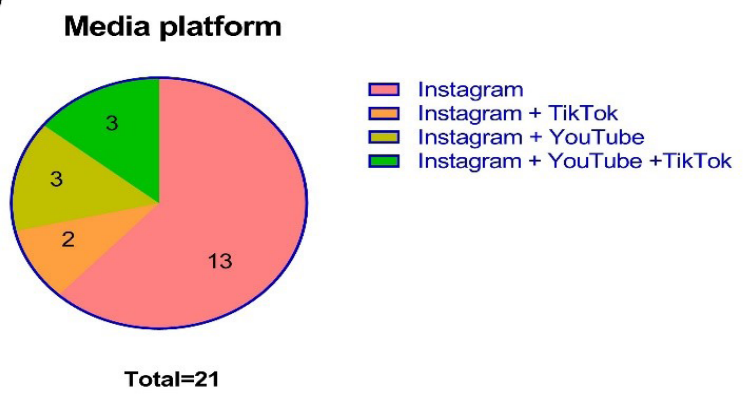

Figure 1. Ambassador knowledge and material. (a) The post-test score was significantly improved after attending an online seminar $(\mathrm{p}<0.05)$. (b) Media platform that used by ambassador for health education.

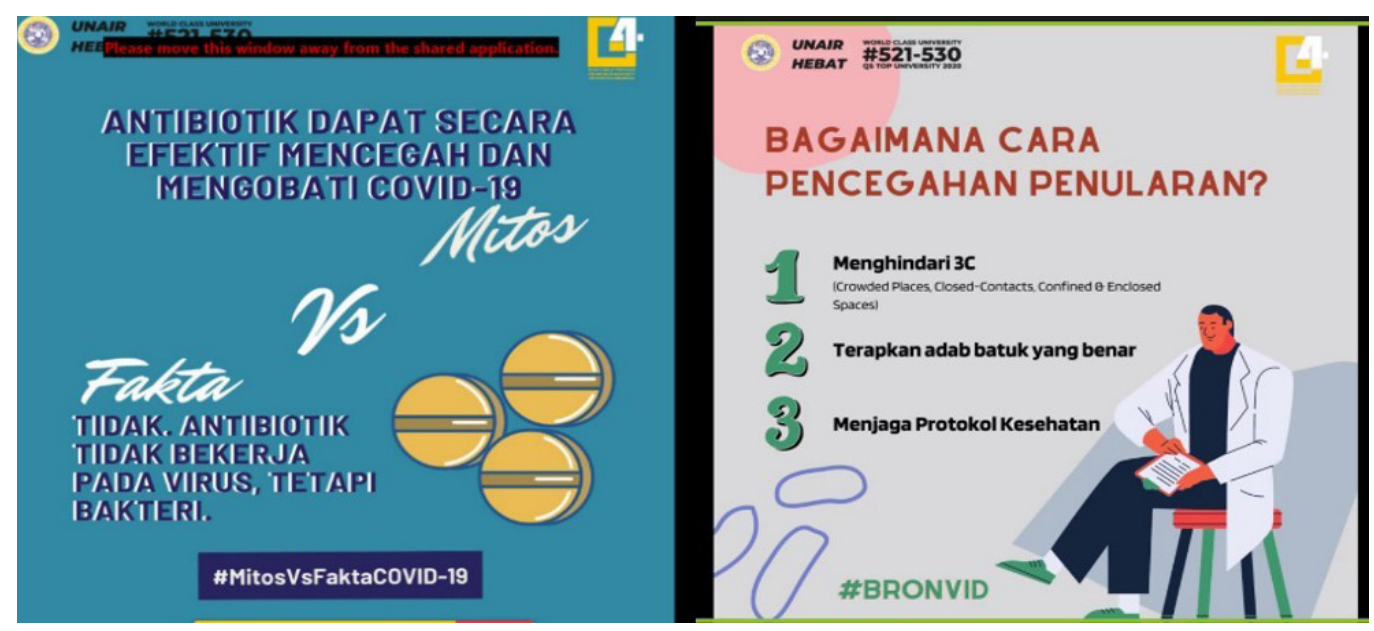

Figure 2. One of the ambassador educational poster

(a)

\section{Evaluation of Ambassador's Material}

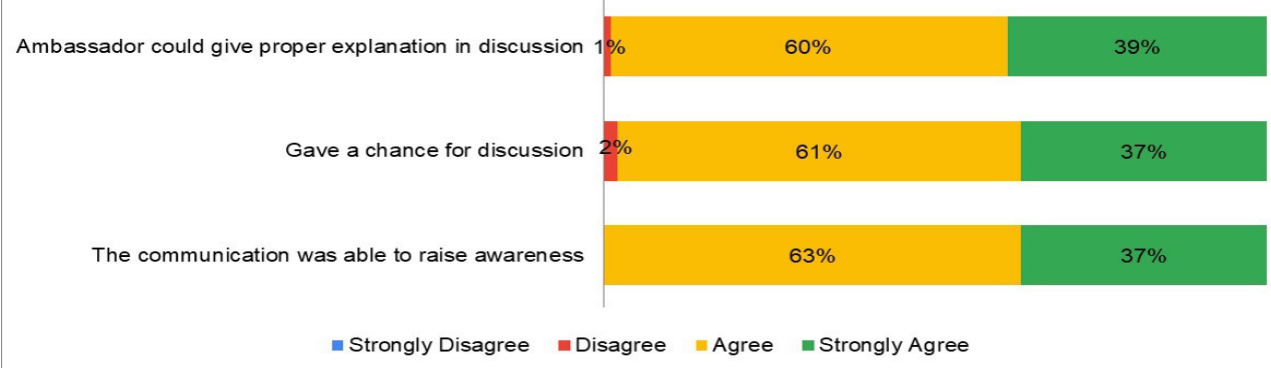

(b)

Awareness toward "Hoaxes" after education

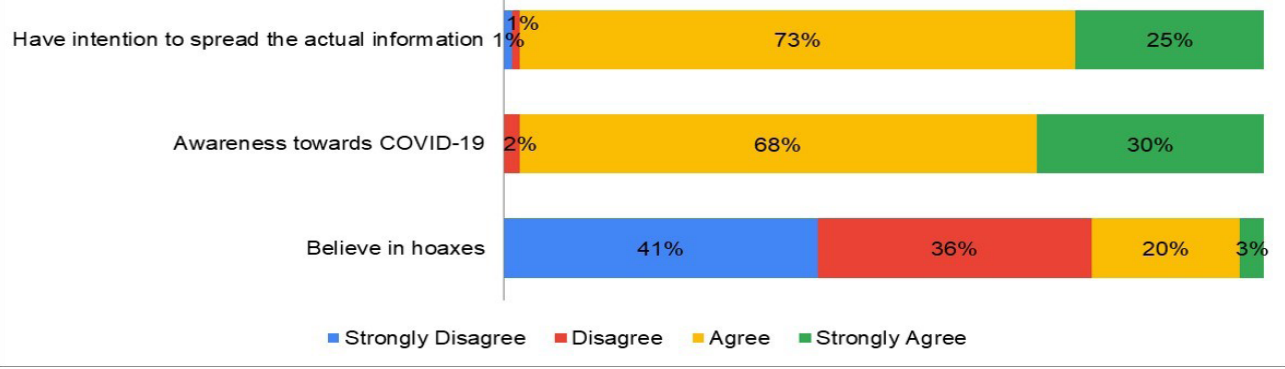

Figure 3. Respondent online answer after given education by the ambassador.(a) Evaluation of ambassador educational material; (b) Respondent awareness after receiving explanation. 


\section{Discussion}

Health promotion has a major point to empower people to increase control over their health in which become way more critical at such crisis time. Health promotion often interchangeably with health education, which providing information and skills to adopt health behavior voluntarily to individuals and the community. Whereas health promotion has a much broader perspective through multisectoral approaches. Still, informing the risk is not equally changing people's behavior. Since the beginning or even things had become pandemic, there are numbers of people that continue not strictly follow the recommendation. ${ }^{13,14}$ The amount of overwhelming news over the media added with the preventive measures that are taken also creates anxiety. A certain degree of concern is needed to strive prevention, but too much anxiety can trigger contradicting defensive cognitive to cope the perceived threat. ${ }^{15}$ An individuals' emotion responses upon a risk sometime is used to guide judgement at a second stage. When negative emotion increase, people may rely on negative information related COVID-19 than real information to make decision. Another challenge is the 'optimism bias': to belief the mischief less likely fall on oneself than others, that can lead into underestimation of situation. ${ }^{16}$

In this study, we demonstrated that the support of the young generation in dealing the mis/disinformation is one of the ways to help health promotion. The ambassador, who predominantly are non-medical related persons, displayed an average knowledge of COVID-19 before receiving the course. The ambassador's insight on how virus flying in the air, only affected certain people, and herbs to treat virus might show similar public perception. Towards the end of the seminar, they visibly showed improvement of knowledge and could modify educational content hence appealing to the audiences. Alongside with respondents that had never received comprehensive COVID-19 information before, there are many factors that can contribute to this condition, either from the environment or individual knowledge resistance. ${ }^{13}$ The majority of participants of this study were young adulthood, and the comprehension was tend likely affected by several psychological factors in the way youth responding to the COVID-19 issue. Their belief of COVID-19 severity, including the symptoms, are less serious in young age group to the social responsibility values might be associated with their intention to find out more from credible sources. ${ }^{17}$

All ambassadors conveyed their health education via offline (face-to-face) and various social media platforms, instant messaging, while few added combinations with video on YouTube. They open two-ways discussion with the audience to make sure that they get a proper comprehension. As we have known, social networks able to transmit good news and bad news universally. A meta-analysis reported that majority of health information problem is on the internet, more prominent on vaccine and infectious disease and the agents are usually individuals. 18 The 'hoax' can spread promptly as the virus itself. By increasing the frequency of clarification, eventually, people are becoming good at reducing their belief in misinformation when faced with a clear evidence-based correction immediately. Whereas, when the information is not corrected immediately, the idea might already integrated into the representation issue. ${ }^{19,20}$ Our result found that after receiving the explanation, some of the respondents still seem to agree with fake news. Even so, we cannot make sure either the respondent misunderstood the question or it was not incidental as well as the most common fake news that respondent still agree with.

This recent study implied that many people in Indonesia have not got accurate information related COVID-19. This group of the population can be an excellent target for health literacy improvement that promotes health promotion. Human as social creature is displayed through the idea that perceived norms will become most influential with whom common identities are shared. From there, we might expect spreading messages from their own community may elicit a more effective result. There is an implication that a larger portion of intervention can spread not directly from the person who receives the action but indirectly from their social contacts who copied the behavior. Thus, targeting well-connected individuals and make their behavior change notable to others may uplift the impact of behavior change. ${ }^{16}$ From here we believe assessing the young generation to educate their close circle and wider community will be more effective than depending medical worker. In addition, ventures to debunk the myths also on purpose to shed social stigma. The discrimination and fear could drive people to hide the illness, prevent them to seek health treatment immediately. ${ }^{11}$

This study has several limitations. The conducted study time was brief for health education from the ambassador. The number of respondents that we collected may not be able to represent the population. A long time of health education might gain more positive results.

\section{Conclusion}

As part of the COVID-19 hoax countermeasures activity, the online seminar, attended by students, shows some positive impacts both for the ambassadors and society. The students exhibit the broadening of comprehension related to COVID-19. Furthermore, the inauguration of students as a spokesperson of health promotion for their surroundings elevates their social responsibility value. Social media use to disseminate accurate information against COVID-19 hoaxes can reach a wider audience, mainly teenagers group. The respondents who receive the correct information from the ambassadors are becoming

\section{Conflict of Interest}

The author stated there is no conflict of interest

\section{References}

1. WHO. Timeline: WHO's COVID-19 response. 2020.

2. WHO. Coronavirus disease 2019 (COVID-19) Situation Report -86. 2020 .

3. Kouzy R, Abi Jaoude J, Kraitem A, et al. Coronavirus Goes Viral: Quantifying the COVID-19 Misinformation Epidemic on Twitter. Cureus. 2020; 12: e7255.

4. Atehortua NA and Patino S. COVID-19, a tale of two pandemics: novel coronavirus and fake news messaging. Health Promot Int. 2020.

5. Chou WS, Oh A and Klein WMP. Addressing Health-Related Misinformation on Social Media. JAMA. 2018; 320: 2417-8.

6. UNESCO. United Nations Educational SaCO. Journalism, 'Fake News' \& Disinformation. France: UNESCO, 2018.

7. Olivia S, Gibson $\mathrm{J}$ and Nasrudin Ra. Indonesia in the Time of 
Covid-19. Bulletin of Indonesian Economic Studies. 2020; 56: 14374.

8. Djalante R, Lassa J, Setiamarga D, et al. Review and analysis of current responses to COVID-19 in Indonesia: Period of January to March 2020. Progress in Disaster Science. 2020; 6: 100091-.

9. Anjarie D, Fressi A and Fitri W. Exploring the Impact of COVID-19 Hoax on the Mental Health of Millennial Moms. KnE Social Sciences. 2021; 4.

10. Betz CL. Generations X, Y, and Z. J Pediatr Nurs. 2019; 44: A7-A8.

11. WHO. Social Stigma associated with COVID-19. 2020.

12. Sahoo S, Padhy SK, Ipsita J, Mehra A and Grover S. Demystifying the myths about COVID-19 infection and its societal importance. Asian J Psychiatr. 2020; 54: 102244-.

13. Van den Broucke S. Why health promotion matters to the COVID-19 pandemic, and vice versa. Health Promot Int. 2020; 35: 181-6.

14. Kumar S and Preetha G. Health promotion: an effective tool for global health. Indian J Community Med. 2012; 37: 5-12.

15. Croyle RT, Sun YC and Hart M. Processing risk factor information: defensive biases in health-related judgments and memory. In: Petrie KJ and Weinman J, (eds.). Perceptions of health and illness : current research and applications. Amsterdam :: Harwood Academic Publishers, 1997.

16. Bavel JJV, Baicker K, Boggio PS, et al. Using social and behavioural science to support COVID-19 pandemic response. Nature Human Behaviour. 2020; 4: 460-71.

17. Oosterhoff B and Palmer CA. Attitudes and Psychological Factors Associated With News Monitoring, Social Distancing, Disinfecting, and Hoarding Behaviors Among US Adolescents During the Coronavirus Disease 2019 Pandemic. JAMA pediatrics. 2020.

18. Wang Y, McKee M, Torbica A and Stuckler D. Systematic Literature Review on the Spread of Health-related Misinformation on Social Media. Soc Sci Med. 2019; 240: 112552.

19. Walter N and Tukachinsky R. A Meta-Analytic Examination of the Continued Influence of Misinformation in the Face of Correction: How Powerful Is It, Why Does It Happen, and How to Stop It? Communication Research. 2019; 47: 155-77.

20. Swire-Thompson B and Lazer D. Public Health and Online Misinformation: Challenges and Recommendations. Annu Rev Public Health. 2020; 41: 433-51. 